\title{
Nitric Oxide as a Pro-apoptotic as well as Anti-apoptotic Modulator
}

\author{
Byung-Min Choi ${ }^{\S}$, Hyun-Ock Pae ${ }^{\S}$, Seon Il Jang, Young-Myeong Kim ${ }^{\dagger}$ and Hun-Taeg Chung* \\ Department of Microbiology and Immunology, Wonkwang University, School of Medicine, Iksan, Chunbug, Korea \\ ${ }^{\S}$ Medicinal Resources Research Center (MRRC), Wonkwang University, Iksan, Chunbug, Korea \\ Department of Molecular and Cellular Biochemistry, College of Natural Sciences, \\ Kangwon National University, Chunchon, Kangwon-do, Korea
}

Received 8 November 2001

\begin{abstract}
Nitric oxide (NO), synthesized from L-arginine by NO synthases, is a small, lipophilic, diffusible, highly reactive molecule with dichotomous regulatory roles in many biological events under physiological and pathological conditions. NO can promote apoptosis (pro-apoptosis) in some cells, whereas it inhibits apoptosis (anti-apoptosis) in other cells. This complexity is a consequence of the rate of NO production and the interaction with biological molecules such as metal ion, thiol, protein tyrosine, and reactive oxygen species. Long-lasting overproduction of NO acts as a pro-apoptotic modulator, activating caspase family proteases through the release of mitochondrial cytochrome c into cytosol, up-regulation of the p53 expression, and alterations in the expression of apoptosisassociated proteins, including the Bcl-2 family. However, low or physiological concentrations of NO prevent cells from apoptosis that is induced by the trophic factor withdrawal, Fas, TNF $\alpha / A c t D$, and LPS. The antiapoptotic mechanism is understood on the basis of gene transcription of protective proteins. These include: heat shock protein, hemeoxygenase, or cyclooxygenase-2 and direct inhibition of the apoptotic executive effectors caspase family protease by $S$-nitrosylation of the cysteine thiol group in their catalytic site in a cell specific way. Our current understanding of the mechanisms by which NO exerts both pro- and anti-apototic action is discussed in this review article.
\end{abstract}

Keywords: Nitric oxide (NO), NO synthase, Apoptosis, Caspase, cGMP/PKG pathway, S-nitrosylation

*To whom correspondence should be addressed.

Tel: 82-63-850-6762; Fax: 82-63-851-5066

E-mail: htchung@wonkwang.ac.kr

\section{Endogenous NO production and NO donors}

Endogenous nitric oxide (NO) is synthesized from the Larginine by a family of NO synthase (NOS) isoenzymes [endothelial NOS (eNOS), neuronal NOS (nNOS) and inducible NOS (iNOS)] (Ignarro et al., 1987; Nathan, 1992). The NOS isoforms are denoted by descriptive terms, based on the requirement of intracellular calcium transients for full activity. Constitutive NOS (cNOS), such as eNOS and nNOS, is activated by a transitory increase generally in cytosolic calcium, which promotes the release of NO over several minutes. Aktdependent phosphorylation and translocation to the cytoplasmic membrane can also activate eNOS. A cytokine-inducible NOS isoform is expressed in many cells including macrophages and hepatocytes after the stimulation of immunological or inflammatory reactions. This produces large amounts of NO for several days (Moncada et al., 1991; Kim, 1995). These characteristics suggest another classification of the isoforms into low- or high-output NOS for endogenously synthesized NO. NOS inhibitors, such as N-monomethyl-L-arginine (LNMMA), are widely used to inhibit NO synthesis, thus allowing the contribution of the effects of NO on the overall response to be assessed (Palmer et al., 1988).

To know the effects of NO on the cell survival, or without the involvement of NOS, NO-releasing compounds (NO donors) are valuable tools (Noack and Murphy, 1991). They preserve $\mathrm{NO}$ in their molecular structure and exhibit biological activity after decomposition. These chemicals exhibit considerable variation in their structure, stability, and biological activity. Different bioavailability arises from the differences in bioactivation and enzymatic versus nonenzymatic NO release. Examples are organic nitrates, 3morpholinosydnonimine (SIN-1), sodium nitroprusside (SNP), S-nitrosothiols (e.g. S-nitrosoglutathione) (GSNO), Snitroso-N-acetylpenicillamine-amine (SNAP), and $\mathrm{S}$ nitrocysteine (CysNO), as well as compounds that contain the $\mathrm{N}(\mathrm{O}) \mathrm{NO}$-functional group, such as the diethylamine-nitric oxide compound (DEA-NO) and spermine-NO. 


\section{Biological Activities of NO}

NO is a diffusible multifunctional transcellular messenger that has been implicated in numerous physiological and pathological conditions. The biological activities of NO can be divided into cGMP-dependent and cGMP-independent pathways (Schmidt and Walter, 1994; Schmidt et al., 1993). $\mathrm{NO}$ is a transducer of the vasodilator message from the endothelium to the vascular smooth muscle. It is also a neurotransmitter in the central and peripheral nervous systems, and participates in non-specific immune responses. Even though NO can affect the cellular functions through posttranslational modifications of proteins directly (i.e. nitrosylation and nitration) and indirectly (i.e. methylation and ribosylation), the main physiological signaling pathway of NO is considered to be the activation of guanylate cyclase, formation of cGMP, and concomitant protein phosphorylation (Schmidt, 1992). The reactions with oxygen, superoxide, and transition metals are more relevant for understanding the cytostatic or cytotoxic signals. The reaction products -NOx, peroxynitrite $\left(\mathrm{ONOO}^{-}\right)$and metal-NO adduct, respectivelysupport additional reactions through their interaction with targets via redox and additive chemistry (Stamler, 1994). Examples of the toxic actions of NO are neurodegenerative diseases, or pancreatic $\beta$-cell destruction. Mechanistically, the diffusion limited reaction of NO with superoxide that is known to generate $\mathrm{ONOO}^{-}$, inhibition of FeS-enzymes (such as the Krebs-cycle aconitase), complexes I and II of the mitochondrial respiratory chain, or ribonucleotide reductase, deregulation of poly(APP-ribose) polymerase, and energy depletion are all reported as probable causes for cell death. Furthermore, NO can regulate apoptotic signaling cascade by the regulation of several gene expressions, mitochondrial dysfunction, and caspase activity/activation (Brune et al., 1995; Kronke et al., 1995).

\section{Cell death: apoptosis versus necrosis}

Cell death is believed to occur by either necrotic or apoptotic mechanisms (Wyllie et al., 1980; Thompson, 1995; Her et al., 1998). These are two distinct forms of cell death, which have different defining morphological and molecular features, and implications for the surrounding tissue. Apoptosis, or programmed cell death, is a strictly regulated device that is responsible for the ordered removal of superfluous, aged, or damaged cells (Kroemer et al., 1995; Thompson, 1995). Morphologically, in cells undergoing apoptosis there is ruffling, blebbing, and condensation of the plasma and nuclear membranes, and subsequently aggregation of the nuclear chromatin. Mitochondria and ribosomes retain their gross structure, and at the least, partial function. There is also disruption of the cytoskeletal architecture. The cell shrinks, and then fragments into a cluster of membrane-enclosed "apoptotic bodies" that are rapidly ingested by adjacent macrophages or other neighboring phagocytic cells. As these apoptotic bodies induce no significant cytokine release by the phagocytic cells, the process progresses without concomitant induction of an inflammatory response. Apoptotic cells display a characteristic fragmentation pattern of DNA into distinct segments that can be visualized as a ladder of bands by gel electrophoresis. However, the DNA ladder formation is not ultimately required or causatively linked to the death process.

Necrosis, on the other hand, can be classified as a form of cell death quite different from apoptosis. Cell necrosis appears to be an unregulated, passive process that is triggered by nonphysiological stimuli, including chemotherapeutic agents. Necrosis does not require energy or the synthesis of proteins and nucleic acids. Morphologically, there are early mitochondrial swelling and failure, dysfunction of the plasma membrane with loss of homeostasis, cell swelling, and rupture. This reaction usually elicits an inflammatory response followed by macrophage phagocytosis.

Apoptosis is biologically initiated by the ligation of specific receptors of the tumor necrosis receptor (TNF-R) family (Ashkenazi and Dixit, 1998). These receptors include CD95/ Fas/Apo-1, TNFR1, and the receptor for TRAIL. Ligand binding of the trimerized receptor at the cell surface recruits intracellular adaptor molecules like FADD and TRADD in order to form the death-inducing signaling complex (DISC) (Boldin et al, 1996; Muzio et al., 1996). Autoactivation of caspase- 8 is thought to follow the interaction with the DISC, and cleaves cytosolic Bid to generate a p15 fragment. This fragment translocates to mitochondria and induces the cytochrome c release, which leads to the activation of downstream caspases (Chinnaiyan et al., 1995; Hsu et al., 1995). The main mitochondrial feature of apoptosis is the permeabilization of the mitichondrial membrane (Jacotot et al., 1999). Mitochondrial dysfunction, or permeability transition pore (PTP), can be caused by several second messengers (calcium, ceramid derivatives, and reactive oxygen species) and pro-apoptotic proteins (Bax, Bak, Bid, and caspases) (Jacotot et al., 1999). This allows the escape of cytochrome c (Kim et al., 2000a). When released from mitochondria, cytochrome $\mathrm{c}$ induces oligmerization of Apaf1 , which recruits and activates procaspase- 9 in the presence of ATP in a complex called the apoptosome (Lui et al., 1996; Susin et al., 1999; Green, 2000). Caspase-9 activates downstream caspases, including procaspase-3 that are responsible for the cytological changes characteristic of apoptosis. Active caspase-3 preferentially cleaves the inhibitor of caspase-activated DNase (ICAD), and allows the translocation of the activated $\mathrm{CAD}$ into the nucleus, resulting in DNA degradation. Therefore, the main biochemical feature of the apoptotic process is the activation of a set of caspase family proteases, and the release of mitochondrial cytochrome c to cytosol. 


\section{NO as a pro-apoptotic inducer}

Since NO is enzymatically synthesized from L-arginine in macrophages, the immunological function of $\mathrm{NO}$ revealed the induction of cytotoxicity against tumor cells and surrounding tissues (Drapier et al., 1988; Drapier and Hibbs, 1986). High concentrations of $\mathrm{NO}$ or peroxynitrite induce cell death, if not by apoptosis, then by necrosis. However, NO induces biochemical characteristics of apoptosis in several cell types. These include macrophages (Albina et al., 1993; Messmer et al., 1996), thymocytes (Fehsel et al., 1995), pancreatic islets (McKaniel et al., 1997), certain neurons (Heneka et al., 1998), and tumor cells (Cui et al., 1994). Although the precise mechanism that determines the cellular sensitivity against NO-induced apoptosis are not clearly elucidated, the proapoptotic effects of $\mathrm{NO}$ on these cells seem to be independent (but not all) of the cGMP accumulation through the activation of soluble guanylate cyclase. The factors affecting cell-specific sensitivity to NO-mediated apoptosis can be associated with the redox state within the cells, activation of the apoptotic signaling cascade (such as caspases) (Kim et al., 2000b), the mitochondrial cytochrome c release (Brown and Borutaite, 1999), or regulation of cell survival and apoptotic gene expression (Kim et al., 1977b; Tamatani et al., 1998). The induction of apoptosis often requires exposure to high levels of exogenous NO donors (Messmer et al., 1995), which may overwhelm the natural protective mechanism of cells. This leads to the activation of the apoptotic-signaling pathway. Such toxic levels of NO may have limited relevance to the in vivo situation. Furthermore, the threshold of the NO level triggering apoptosis is different from one cell to the other.

Activation of mitochondrial apoptotic pathway Apoptotic cell death is directly linked to the mitochondrial cytochrome c release into cytosol, and the activation of apoptotic signaling and executive effectors caspase family proteases (Yang et al., 1997). Cytotoxic ligand-induced death receptor activation causes apoptotic cell death through caspase-8 activation, Bid cleavage, cytochrome $\mathrm{c}$ release, activation of caspase- 9 and -3 , and finally activation of CAD (caspase-dependent activated DNase) (Kim et al., 2000c). In contrast, NO can directly induce cytochrome $\mathrm{c}$ release through the potential loss of the mitochondrial membrane, without caspase- 8 activation and Bid cleavage (Brookes et al., 2000). The cytosolic cytochrome c activates the caspase-dependent apoptotic signal cascade, resulting in the degradation of the inhibitor of caspaseactivated DNase (CAD), activation of CAD, and DNA fragmentation (Sakahira et al., 1998). NO reversibly binds to mitochondrial iron-sulfur cluster-containing enzymes, such as aconitase and complexes I \& II of the mitochondrial respiratory chain, and inhibits the ATP generation (Drapier $e t$ al., 1988; Drapier and Hibbs, 1986). NO also binds to cytochrome c oxidase (complex IV) in the mitochondrial electron transfer chain (Poderoso, et al., 1996). Under these conditions, superoxide that is generated from mitochondria interacts with NO to form cytotoxic peroxynitrite. Indeed, peroxynitrite induces both the nitration of the tyrosine residue in proteins and the apoptotic cell death in thymocytes (Salgo et al., 1995), neuronal cells (Bonfoco et al., 1995), and HL-60 cells, as well as U-937 cells (Lin et al., 1995). However, the physiological relevant concentration of peroxynitrite induces apoptosis in HL-60 human leukemia cells and the transformed cell line, U-937 cells, but fails to affect normal human endothelial and mononuclear cells (Lin et al., 1995). It suggests that abnormal cells are more sensitive to peroxinitrite-induced cytotoxicity than normal cells. Recent evidence shows that the simultaneous generation of $\mathrm{NO}$ and superoxide protects RAW264.7 cells from NO-induced apoptosis (Brune et al., 1997). This suggests that the central role of peroxynitrite may be the nitration of the tyrosine residue or neutralization of $\mathrm{NO}$ toxicity. Thus, it indicates that the proapoptotic effects of $\mathrm{NO}$ on some cells are likely linked to the mitochondrial cytochrome $\mathrm{c}$ release through mitochondria membrane potential loss, and the effect of NO on the cytochrome $\mathrm{c}$ release depends on the levels of redox potential and target molecules (such as iron, glutathione, and superoxide) within cells.

Activation of caspase signaling pathway by NO-induced p53 expression The expression of the tumor suppressed gene, p53, is linked to apoptosis in tumor cells that are exposed to DNA damaging agents. Cytotoxic effects of NO and peroxynitrite on tumor cells are the result of DNA damage (Tamir et al., 1996; Cai et al., 2000). NO-mediated DNA damage results in the accumulation of p53 (Messmer and Brune, 1996), which has been described as an essential indicator of NO-mediated apoptosis. NO-mediated p53 accumulation induces cell cycle arrest by $\mathrm{p} 21$ up-regulation, or apoptosis by Bax up-regulation (Kolb, 2000). The exposure of macrophage RAW 264.7 cells and insulinoma RINm5F cells to high levels of the exogenous NO donor induces apoptosis with p53 accumulation, p21 up-regulation, increase in ratio of $\mathrm{Bax} / \mathrm{Bcl}-\mathrm{xL}$, cytochrome $\mathrm{c}$ release, and caspase activation. Furthermore, the treatment of RAW264.7 cells with LPS plus IFN- $\gamma$ induces p53 accumulation and apoptosis, which were suppressed by the NOS specific inhibitor NMMA (Messmer et al., 1996). In addition, p53 antisense RNAexpressing RAW264.7 cells appeared significantly resistant (not completely) towards endogenous NO (Messmer and Brune, 1996). It indicates that p53 accumulation plays a critical role in NO-induced apoptotic cell death. The use of a caspase inhibitor suppressed NO-mediated apoptosis cell death, but did not change the cytochrome $\mathrm{c}$ release and expression levels of $\mathrm{Bcl}-\mathrm{xL}$ and Bax. This suggests that caspase activation is downstream of the cytochrome $\mathrm{c}$ release and Bax (Brockhaus and Burne, 1999). This evidence indicates that NO-mediated apoptosis is entirely controlled by the mitochondrial pathway with the implication that cytochrome c relocation demands p53 accumulation. 
However, the exposure of the p53 negative human promyelocytic leukaemia cell line U937 to $1 \mathrm{mM}$ GSNO resulted in apoptotic cell death with DNA ladder formation (Messmer and Brune, 1996). This suggests that the p53-independent signaling pathways (eg, direct release of cytochrome $\mathrm{c}$ or MAP kinase pathway) can be operative during NO-mediated apoptosis.

It is interesting that the caspase activation and the degradation of classical biosubstrates, including PARP, can occur both in p53-dependent and p53-independent NOmediated apoptotic cell death by NO (Messmer et al. 1996). The simplest model to combine p53-dependent and p53independent NO-signaling events is their convergence upon a final damaging or executive pathway. Caspase inhibitors strongly inhibit apoptotic cell death in p53-dependent and p53-independent cells. This suggests that caspase activation is a common mediator of the apoptotic-signaling pathway, even though NO can initially induce diverse upstream signaling pathways. It seems that the diverse apoptotic signaling mechanism would be integrated at a point that would result in proteolytic events, such as caspase activation. In addition, the promoters of iNOS and eNOS p53 contain a specific binding site for the tumor suppressed protein p53 (Forrester et al., 1996; Mortensen et al., 1999). Accumulation of p53 in cells down-regulates the expression of eNOS and iNOS, which results in the suppression of NO production. This regulation may be important, both for regulating apoptosis and avoiding the generation of genotoxic quantities of NO.

Activation of JNK/SAPK and p38 kinase The c-Jun Nterminal kinase (JNK)/stress-activated protein kinase (SAPK) group of mitogen-activated protein kinases (MAPKs) is activated in mammalian cells by environmental stress, inflammatory cytokines, anti-cancer drugs, and mitogenic stimuli. Recent studies demonstrate that JNK/SAPK regulates the activities of many transcription factors. Also, the JNK/ SAPK pathway is required for the regulation of inflammatory responses (Liu et el., 1996), cell proliferation (Minden et al., 1995), and apoptosis (Verheij et al., 1996; Kim et al., 199a). It is clear that the effects of JNK/SAPK on apoptotic signaling strongly depend on the cell type and the context of other regulatory influences that the cell is receiving. The involvement of JNK/SAPK in apoptotic cell death is particularly intriguing, and recently has been studied in the area of NO-mediated cytotoxicity. Recent studies demonstrate that the NO donor induces the stimulation of JNK/SAPK in intact cells (Lander et al., 1996; Kim et al., 1997a). NO that is produced from HEK293 cells expressing NOS increases JNK/ SAPK activity, and the NOS inhibitor abrogated this increased activity. The treatment of RAW 264.7 cells with SNP induced apoptosis with the activation of both JNK/SAPK and p38, and caspase-3 activation (Jun et al., 1999a). The suppression of JNK/SAPK and p38 activity by PKC transfection protected RAW 264.7 cells from SNP-mediated apoptosis. This indicates that JNK/SAPK may be a critical mediator for the
NO-induced apoptosis. However, NO donors induced caspase-3-dependent apoptotic cell death with strong activation of the p38 kinase, but did not activate JNK/SAPK and extracellular signal-regulated kinase (ERK) (Jun et al., 1999b; Oh-hashi et al., 1999) in HL60 and dopamine neuronal SH-SY5Y cells. The inhibition of p38 activity with B202190 suppressed the activation of caspase 3-like proteases, as well as the cell death. The sustained activation of JNK/SAPK and p38 MAPK contributes to NO-mediated apoptosis by activation of caspase- 3 through the release of mitochondrial cytochrome c into the cytosol (Tournier et al., 2000; Assefa et al., 2000). These results suggest that the activation of JNK/SAPK and p38 MAPK is an important pathway of NO-mediated apoptotic cell death, mainly by the mitochondria-dependent caspase activation.

Apoptotic signaling by NO/cGMP pathway NO activates soluble guanylate cyclase by interaction with its heme moiety and generates cGMP, which is a well-known cellular mediator for the NO-mediated physiological phenomena. Although NO directly induced apoptosis via the cytochrome c release, p53 accumulation, and JNK/SAPK activation, the NO/cGMP pathway has also been shown with either pro-apoptotic or anti-apoptotic functions. Its anti-apoptotic mechanism will be discussed later. The incubation of cardiomyocytes and pancreatic B-cell line (HIT-T15) with SNAP induces both apoptosis and necrosis (Taimor et al., 2000; Shimojo et al., 1999; Loweth et al., 1997). The induction of apoptosis, but not necrosis, can be blocked by the inhibition of soluble guanylyl cyclase ODQ or the cGMP-dependent protein kinase G (PKG), KT5822 (Taimor et al., 2000; Loweth et al., 1997). The cGMP analogues or YC-1 (a direct activator of soluble guanylate cyclase) induces apoptosis in cardiomyocytes (Taimor et al., 2000), human colon cells (Soh et al., 2000), pulmonary artery smooth muscle cells (Chiche et al., 1998), neuronal cells (cortical neurons and hippocampal nerve cells) (Li et al., 1997a), and HIT-T15 (Loweth et al., 1997). The cGMP analogue-induced apoptosis is inhibited by the PKG inhibitor (Loweth et al., 1997). These observations suggest an important role for PKG in the regulation of apoptosis by the NO/cGMP pathway. Although the apoptotic signal pathway of cGMP has not been clearly elucidated, cGMP can mediate apoptosis through the activation of PKG, which then activates the MEKK1-SEK1-JNK1 cascade (Soh et al., 2000).

Apoptosis by NO-mediated ceramide generation Sphingolipid metabolites, including ceramide, have been implicated as potential regulatory molecules in signal transductions that involve apoptotic cell death. Apoptosisinducing stresses such as tumor necrosis factor- $\alpha$ (Kolesnick and Golde, 1994), anti-Fas antibody (Tepper et al., 1995), ionizing radiation (Huang et al., 1997), serum deprivation (Hannun, 1994; Mathias et al., 1998), anti-cancer drugs (Strum et al., 1994; Bose et al., 1995), heat shock (Chang et al., 1995), and hydrogen peroxide (Verheij et al., 1996) have 
been reported to increase intracellular ceramide. NO-induced apoptosis requires the generation of ceramide. For example, exposure of HL-60 cells and renal mesangial cells to NO donors increases the magnesium-dependent neutral sphingomyelinase (N-SMase) activity (neither acid SMase nor magnesium-independent N-SMase activity), cellular ceramide, and casdpase-3 activity (Huwiler et al., 1999; Takeda et al., 1999). Ceramide formation can induce several apoptototic signal pathways, including the release of mitochondrial cytochrome $\mathrm{c}$ into the cytosol, the activation of caspases-9 and -3 (Sawada et al., 2000), the inhibition of protein kinase B/Akt (Schubert et al., 2000), the activation of caspase-8 and -3 (Wang et al., 2000), and the suppression of the Bcl-2 expression (Di Nardo et al., 2000). The complexity of ceramide generation, and activation of the apoptoticsignaling cascade in NO-generating systems, should be clearly elucidated in the near future.

\section{NO as an anti-apoptotic modulator}

Although NO promotes apoptosis in some cells, it becomes apparent that NO displays antiapototic properties in other cell types. These include hepatocytes (Kim et al., 1997b; Saavedra et al., 1997), human B lyphocytes (Mannick et al., 1994), endothelial cells (Dimmelder et al., 1997; Kwon et al., 2000), splenocytes (Genaro et al., 1995), eosinophils (Beauvais et al., 1995; Hebestreit et al., 1998), and PC12 cells (Kim et al., 1999). In the animal model, the lipopolysaccharide (LPS)induced hepatic apoptosis increased by the administration of NOS inhibitors. The administration of a liver-specific NO donor almost completely suppressed the caspase-3-like activity, and the massive hepatic apoptosis that is induced by the administration of TNF $\alpha$ plus D-galactosamine (Kim et al., 1997c; Ou J Carolos et al., 1997). In addition, NO can protect some cells from apoptosis that is induced by many different types of stimuli. These include TNF $\alpha$ (Kim et al., 1997b; Saavedra et al., 1997; Kim et al., 2000b), oxidative stress (Kim et al., 1995a), serum-deprivation (Kim et al., 1995b; Kwon et al., 2000), and anoxia (Madesh et al., 1999). This evidence shows that NO inhibits apoptosis both in vitro and in vivo in certain cell types and experimental conditions. The biochemical mechanism underlying the NO-mediated antiapoptotic effects may be cell-type specific with multiple pathways. For example, NO blocks apoptosis in PC12 cells, predominantly via the NO/cGMP/PKG pathway (Kim et al., 1999), and inhibits hepatocyte apoptosis, both through cGMPdependent interruption of apoptotic signaling and direct inhibition of caspase activity (Kim et al., 1997c). NO that is generated either by the NO donor or NOS can block apoptosis. For example, in endothelial cells, the low level of NO from eNOS blocks TNF $\alpha$-induced (Dimmeler et al., 1997) and serum-deprived apoptosis (Kwon et al., 2000). Also, a high level of NO from iNOS transfection and NO donor inhibits LPS-induced and serum-deprived apoptosis (Tzeng et al., 1997; Ceneviva et al., 1998). The precise mechanisms for the NO-mediated inhibition of apoptosis have not been clearly elucidated. However, a series of molecular targets (such as iron-sulfur complexes, soluble guanylate cyclase, caspases, and glutathione in varying in cell types and apoptotic stimuli) for NO were identified. They can suppress apoptotic cell death either by indirect or direct interaction with the apoptotic-signaling cascade.

\section{Inhibition of apoptotic signaling by NO/cGMP pathway} The NO-mediated activation of soluble guanylate cyclase produces. The intracellular elevation of cGMP activates PKG and in turn decreases the cellular $\mathrm{Ca}^{2+}$ concentration, which is one of the key signals of apoptosis. The interference of the NO/cGMP pathway with the apoptotic signal transduction is controversial. Undoubtedly, cGMP production by NO can prevent apoptosis in some cell types including hepatocytes (Kim et al., 1997c; Saavedra et al., 1997), neuronal PC12 cells (Kim et al., 1999b), embryonic motor neurons (Estevez et al., 1998), B lymphocytes (Genaro et al., 1995), eosinophils (Beauvais et al., 1995), and ovarian follicles (Chun et al., 1995). However, some studies showed that the antiapoptotic effect of NO was not abrogated in other cells by the inhibitor of soluble guanylate cyclase, ODG. The stable and membrane permeable cGMP analogue 8-bromo-cGMP also revealed no protective effect from NO (Sata et al., 2000). These indicate that the antiapoptotic mechanisms of NO can be divided into cGMP-dependent and cGMP-independent mechanisms, which are likely cell-type specific. In hepatocytes, PC12 cells and U937 cells with the antiapototic effects of NO are associated with cGMP production, which suppresses the mitochondrial cytochrome c release (Kim et al., 1999; Kwon et al., 2000), ceramide generation (De Nadai et al., 2000), and caspase activation (Kim et al., 1997c; Pastorino et al., 1999). This suppression was reduced by the cGMP-dependent protein kinase (PKG) inhibitor (Pastorino et al., 1999; Kwon et al., 2000). In addition, NO and cGMP protect splenic B lyphocytes from programmed cell death by increasing the expression level of Bcl-2 (Genaro et al., 1995). The molecular mechanism that underlies NO/cGMP-mediated antiapoptosis could, in part, involve the activation of Akt/PKB ( $\mathrm{Li}$ et al., 2000), which induces phosphorylation of Bad and procaspase9 and cytoprotective gene expression through NF-кB activation.

Inhibition of caspase activity by $\mathbf{S}$-nitrosylation Caspases are a family of cysteine proteases that consist of 14 isoforms, which play an essential role in the apoptotic signal cascade. Upon exposure to a proapoptotic signal, the zymogen forms of caspases that are constitutively present in cells become proteolytically cleaved and activated. Initiator caspases (such as caspase-8, -9, and -10) can cleave other caspases, while executioner caspases (including caspase-3, -6, and -7) cleave death substrates (Thornberry et al., 1998; Casciola-Rosen et al., 1996). All caspases contain a single cysteine at the enzyme catalytic site. This thiol is susceptible to redox 
modification and can be effectively modified by Snitrosylation in the presence of NO. Seven members of purified recombinant human caspases that were tested were shown to be susceptible to reversible inhibition by NO through this redox modification (Li et al., 1997b). The ratio of enzyme subunit to S-nitrosylation is stoichiometrically found to be $1: 1$ in recombinant caspase-3 and -8 following SNAP treatment. Evidence for S-nitrosylation of caspase-3 and caspase- 1 has been identified in vivo. By inhibiting caspase activity through the S-nitrosylation of the cysteine within the enzyme active site, NO inhibits apoptosis in hepatocytes (Kim et al., 1997c; 1999b; 2000c), endothelial cells (Tzeng et al., 1997; Ceneviva et al., 1998), and several tumor cell lines (Nannick et al., 1994; Kim et al., 1998) through inhibition of caspase proteolytic activation, as well as by the direct suppression of caspase activity. NO is electronically a neutral molecule. It has weak chemical reactivity with thiol at neutral $\mathrm{pH}$, compared to the highly reactive $\mathrm{NO}$ products with $\mathrm{NO}^{+}-$ like characteristics. $\mathrm{NO}^{+}$can be generated by the loss of one electron from NO. Known electron acceptors are molecular oxygen and transition metal ions such as iron and copper, which readily react with NO in vivo. The S-Nitrosylating species can be generated by the interaction of NO with the iron-sulfur complex (Boese et al., 1995). Therefore, the capacity of NO to S-nitrosylate caspases will depend on the abundance of these molecules, and the availability of other thiol targets such as glutathione and free cysteine. The reaction product of NO and iron-sulfur complexes, dinitrosyliron complexes (DNIC), has been shown to carry out Snitrosylation of caspase and albumin through the formation of $\mathrm{NO}^{+}$(Boese et al., 1995; Kim et al., 2000c). Similarly, Snitrosylation of caspase occurs effectively in iron-rich hepatocytes, but is low in iron-poor MCF-7 and RAW264.7 cells, unless these cells are preloaded with iron (Kim et al., 1998). It indicates that the cellular content of iron-sulfur complexes is a critical factor for NO-mediated S-nitrosylation in vivo. In fact, conversion of heme to non-heme iron by NOmediated hemeoxygenase induction increases DNIC formation (Kim et al., 1995a; b) and protects hepatocytes from apoptosis (Kim et al., 1995a). Because caspases play a critical role in apoptosis that is induced by TNF $\alpha$, Fas, hypoxia, and nutrient deprivation, $\mathrm{NO}$ can be used either for the prevention of unwanted apoptotic cell death, or for a new therapeutic strategy of apoptotic tumor killing through the control of the NO production and cellular iron level.

Inhibition of mitochondrial dysfunction Apoptosis research recently experienced a change from a paradigm in which the nucleus determined the apoptotic process to a paradigm in which caspases, and more recently, mitochondria constitute the center of apoptotic control. Mitochondria play a central role in apoptosis through the opening of the mitochondrial permeability transition pore (MPTP) (Pastorino et al., 1999). The transient MPTP opening is initially caused by the swelling and rupture of the outer membrane to release mitochondrial proteins including caspases (mainly caspases 2, 3 , and 9), caspase activators (cytochrome c, hsp 10), as well as a caspase-independent death effector, AIF (apoptosis inducing factor). Recent studies focused on the release of cytochrome c, which is a key component in the activation of caspase cascade, and sets apoptosis in motion (Yang et al., 1997). Bid, a proapoptotic member of the Bcl-2 family, can be cleaved by caspase-8 after Fas/TNF-R1 engagement (Li et al., 1998; Luo et al., 1998). The $\mathrm{p} 15$ form of truncated Bid (tBid) translocates to mitochondria and induces the cytochrome $\mathrm{c}$ release, which leads to the activation of downstream caspases and apoptosis. We observed that NO blocks the cytochrome $\mathrm{c}$ release by the suppression of Bid cleavage through direct inhibition of caspase- 8 activity (Kim et al., 2000b). In addition, oncoprotein Bcl-2 interacts with the permeability transition pore complex to inhibit membrane permeabilization as well as cytochrome c release. NO can also block the cytochrome $\mathrm{c}$ release by maintaining the Bcl-2 level in both MCF-7 and hepatocytes that are treated with TNF $\alpha$ plus actinomycine D (Kim et al., 1998). Furthermore, the caspase3 inhibitor (Ac-DEVD-cho) can inhibit proteolytic cleavage of Bcl-2 and NO. This suggests that NO may maintain the in vitro steady date level of Bcl-2 through the inhibition of caspase-3-like activity. This evidence suggests that NO can inhibit the cytochrome $\mathrm{c}$ release from mitochondria by the inhibition of cleavage of Bid and Bcl-2, and thus suppresses the apoptotic signal cascade.

Regulation of antiapoptosis-related gene expression by NO $\mathrm{NO}$ and reactive nitrogen intermediates can interact with many different types of biomolecules including glutathione, iron-containing proteins, and tyrosine residue of protein, thereby changing the cellular dedox potential and some signaling events. These oxidative and nitrosative stresses result in several gene expressions that modulate apoptosis. We observed that NO potentially induces cytoprotective proteins such as HSP70 and HSP32 (heme oxygenase), which protect hepatocyte from apoptosis induced by TNF $\alpha$, and oxidative or nitrosative stress (Kim et al., 1995a; 1997b). The NOproducing cytokine protects wild type islet cells from apoptotric cell death through NO-induced HSP70 induction, but it does not protect the iNOS-deficient cells (Liu et al., 2000). The molecular mechanism that underlies the antiapoptotic effect of NO-induced HSP70 may be associated with two possibilities: (1) HSP70 associates with the caspaserecruitment domain (CARD) of Apaf-1 and inhibits the oligomerization of Apaf-1 and the formation of apoptosome with procaspase-9, which results in the suppression of caspase-9 activation (Saleh et al., 2000). (2) HSP70 involves the chaperon-mediated import of precursor proteins into mitochondria, which results in the inhibition of cytochrome $\mathrm{c}$ release that is required for caspase- 9 activation (Mosser et al., 2000).

NO can also regulate the protein levels of the Bcl-2 family proteins. Genaro and his co-worker showed that the NO donor 
protects splenic B-lymphocytes from apoptotic cell death by the elevation of the Bcl-2 expression, both at the mRNA and protein levels (Genaro et al., 1995). NO prevents the release of the mitochondrial cytochrome $\mathrm{c}$ to cytosol by maintaining the steady-state protein level of Bcl-2, thus inhibiting the formation of apoptosome and caspase-9 activation in hepatocytes and MCF-7 cells (Kim et al., 1998).

MAP kinase-dependent phosphorylation processes can interfere with the degradation of the antiapoptotic protein Bcl2. The cytosolic MAP kinase phosphatase MAP kinase phosphatase-3 (MKP-3) induces the apoptosis of endothelial cells in response to TNF $\alpha$ via the dephosphorylation of the MAP kinase ERK1/2, which leads to Bcl-2 proteolysis. Rossig et al. showed that NO down-regulates the MKP-3 protein level by the destabilization of MKP-3 mRNA (Rossig et al., 2000). Moreover, NO prevents the TNF $\alpha$-induced dephosphorylation of ERK1/2, which results in an increase of the Bcl-2 level in endothelial cells. Subsequently, NO protects cells from TNF $\alpha$-induced apoptosis by preventing both the decrease in $\mathrm{Bcl}-2$ protein levels and the mitochondrial cytochrome c release.

\section{Pathophysiological significance of NO-mediated apoptosis and survival}

Homeostasis is maintained through a balance between cell proliferation and cell death. Physiologic cell death occurs primarily through an evolutionarily conserved form of apoptosis. Alterations of the balance between cell proliferation and apoptosis contribute to the pathogenesis of a number of human diseases. NO, synthesized from L-arginine by NOS, can alter this balance, because it prevents or induces apoptosis, depending on cell types and environmental conditions. For example, pathological high amounts of NO act as a proapoptotic modulator that activate caspase family proteases. When NO-mediated apoptosis loses cell population in a certain tissue or organ, it causes several human diseases including atherosclerosis, amyotrophic lateral sclerosis, and neurodegenerative disorders. On the other hand, when appropriate amounts of NO production suppress unwanted apoptotic cell death, it prevents the development of several diseases such as liver failure in sepsis, endothelial cell apoptosis (atherosclerosis and intimal hyperplasia), irradiation-induced tissue damage, and hypoxia-induced neuronal cell death. In contrast, the antiapoptotic effect of NO on DNA-damaged cells, which should die through activation of the apoptotic pathway, contributes to unwanted cell survival and cancer development. However, the pathophysiological significance of NOs apoptotic activity remains to be clearly determined in most human disease cases.

\section{Conclusion}

NO and its related molecules exert double-edged effects on cell death, depending on its rate of production, the redox state of the cells, and cell types. NO activates the apoptotic signal cascade in some situations, whereas it protects cells against spontaneous or induced apoptosis in other cases. Proapoptotic effects of NO are often observed by the formation of highly toxic peroxynitrite from the reaction with superoxide. The major apoptotic pathway of NO may be associated with cytochrome c release through activation of JNK and increase in the p53 expression. p53 transactivates the expression of pro-apoptotic genes, such as bax and that of the cyclindependent kinase inhibitor $\mathrm{p} 21$, whereas it down-regulates the expression of the anti-apoptotic protein $\mathrm{Bcl}-2$. On the other hand, NO directly inhibits the activity of caspases through Snitrosylation of the cysteine thiol at their catalytic site, providing an efficient means to block apoptosis. Other antiapoptotic effects of NO rely on the NO/cGMP-dependent inhibition of the cytochrome $\mathrm{c}$ release, increase in Bcl-2 expression that controls the mitochondrial permeability transition pore, induction of the HSP70 and HSP32, and suppression of the ceramide generation. Further studies are necessary in order to elucidate the biochemical mechanism and pathophysiological significance of NO-mediated pro- and anti-apoptosis, and hence provide the new therapeutic strategy for diseases where an alteration of apoptosis is involved.

Acknowledgments This work was supported by the Medical Resources Research Center and Wonkwang University (2001).

\section{References}

Albina, J. E., Cui, S., Mateo, R. B. and Reichner, J. S. (1993) Nitric oxide-mediated apoptosis in murine peritoneal macrophages. J. Immunol. 150, 5080-5085.

Ashkenazi, A. and Dixit, V. M. (1998) Death receptors: signaling and modulation. Science 281, 1305-1308.

Assefa, Z., Vantieghem, A., Garmyn, M., Declercq, W., Vandenabeele, P., Vandenheede, J. R., Bouillon, R., Merlevede, W. and Agostinis, P. (2000) p38 mitogen-activated protein kinase regulates a novel, caspase-independent pathway for the mitochondrial cytochrome $\mathrm{c}$ release in ultraviolet $\mathrm{B}$ radiationinduced apoptosis. J. Biol. Chem. 275, 21416-21421.

Beauvais, F., Michel, L. and Dubertret, L. (1995) The nitric oxide donors, azide and hydroxylamine, inhibit the programmed cell death of cytokine-deprived human eosinophils. FEBS Lett. 361, 229232.

Boldin, M. P., Goncharov, T. M., Goltsev, Y. V. and Wallach, D. (1996) Involvement of MACH, a novel MORT1/FADDinteracting protease, in Fas/APO-1- and TNF receptor-induced cell death. Cell 85, 803-815.

Bonfoco, E., Krainc, D., Ankarcrona, M., Nicotera, P. and Lipton, S. A. (1995) Apoptosis and necrosis: two distinct events induced, respectively, by mild and intense insults with $\mathrm{N}$ methyl-D-aspartate or nitric oxide/superoxide in cortical cell cultures. Proc. Natl. Acad. Sci. USA 92, 7162-7166.

Boese, M., Mordvintcev, P. I., Vanin A. F., Busse, R. and Mulsch, A. (1995) S-nitrosation of serum albumin by dinitrosyl-iron complex. J. Biol. Chem. 270, 29244-29249.

Bose, R., Verheij, M., Haimovitz-Friedman, A., Scotto, K., Fuks, 
Z. and Kolesnick, R. (1995) Ceramide synthase mediates daunorubicin-induced apoptosis: an alternative mechanism for generating death signals. Cell 82, 405-414.

Brockhaus, F. and Brune, B. (1999) p53 accumulation in apoptotic macrophages is an energy demanding process that precedes cytochrome c release in response to nitric oxide. Oncogene 18, 6403-6410.

Brown, G. C. and Borutaite, V. (1999) Nitric oxide, cytochrome c and mitochondria. Biochem. Soc. Symp. 66, 17-25.

Brookes, P. S., Salinas, E. P., Darley-Usmar, K., Eiserich, J. P., Freeman, B. A. and Darley-Usmar, V. M. (2000) Concentration-dependent effects of nitric oxide on mitochondrial permeability transition and cytochrome c release. J. Biol. Chem. 275, 20474-20479.

Brune, B., Gotz, C., Messmer, U. K., Sandau, K., Hirvonen, M. R. and Lapetina, E. G. (1997) Superoxide formation and macrophage resistance to nitric oxide-mediated apoptosis. $J$. Biol. Chem. 272, 7253-7258.

Brune, B., Messmer, U. K. and Sandau, K. (1995) The role of nitric oxide in cell injury Toxicol. Lett. 82/83, 233-237.

Cai, L., Klein, J. B. and Kang, Y. J. (2000) Metallothionein inhibits peroxynitrite-induced DNA and lipoprotein damage. $J$. Biol. Chem. 275, 38957-38960.

Casciola-Rosen, L., Nicholson, D. W., Chong, T., Rowan, K. R., Thornberry, N. A., Miller, D. K. and Rosen, A. (1996) Apopain/CPP32 cleaves proteins that are essential for cellular repair: a fundamental principle of apoptotic death. J. Exp. Med. 183, 1957-1964.

Ceneviva, G. D., Tzeng, E., Hoyt, D. G., Yee, E., Gallagher, A., Engelhardt, J. F., Kim, Y. M., Billiar, T. R., Watkins, S. A. and Pitt, B. R. (1998) Nitric oxide inhibits lipopolysaccharideinduced apoptosis in pulmonary artery endothelial cells. Am. J. Physiol. 275, L717-L728

Chang, Y., Abe, A. and Shayman, J. A. (1995) Ceramide formation during heat shock: a potential mediator of alpha Bcrystallin transcription. Proc. Natl. Acad. Sci. USA 92, 1227512279.

Chiche, J. D., Schlutsmeyer, S. M., Bloch, D. B., de la Monte, S. M., Roberts, J. D., Filippov, G., Janssens, S. P., Rosenzweig, A. and Bloch, K. D. (1998) Adenovirus-mediated gene transfer of cGMP-dependent protein kinase increases the sensitivity of cultured vascular smooth muscle cells to the antiproliferative and pro-apoptotic effects of nitric oxide/cGMP. J. Biol. Chem. 273, 34263-34271.

Chinnaiyan, A. M., ORourke, K., Tewari, M. and Dixit, V. M. (1995) FADD, a novel death domain-containing protein, interacts with the death domain of Fas and initiates apoptosis. Cell 81, 505-512.

Chun, S. Y., Eisenhauer, K. M., Kubo, M. and Hsueh, A. J. (1995) Interleukin-1 beta suppresses apoptosis in rat ovarian follicles by increasing nitric oxide production. Endocrinology 136, 3120-3127.

Cui, S., Reichner, J. S., Mateo, R. B. and Albina, J. E. (1994) Activated murine macrophages induce apoptosis in tumor cells through nitric oxide-dependent or -independent mechanisms. Cancer Res. 54, 2462-2467.

De Nadai, C., Sestili, P., Cantoni, O., Lievremont, J. P., Sciorati, C., Barsacchi, R., Moncada, S., Meldolesi, J. and Clementi, E. (2000) Nitric oxide inhibits tumor necrosis factor-alpha-induced apoptosis by reducing the generation of ceramide. Proc. Natl.
Acad. Sci. USA 97, 5480-5485.

Dimmelder, S., Haendeler, J., Nehls, M. and Zeiher, A. M. (1997) Suppression of apoptosis by nitric oxide via inhibition of interleukin-1beta-converting enzyme (ICE)-like and cysteine protease protein (CPP)-32-like proteases. J. Exp. Med. 185, 601607.

Di, Nardo, A., Benassi, L., Magnoni, C., Cossarizza, A., Seidenari, S. and Giannetti, A. (2000) Ceramide 2 (N-acetyl sphingosine) is associated with reduction in Bcl-2 protein levels by Western blotting and with apoptosis in cultured human keratinocytes. Br. J. Dermatol. 143, 491-497.

Drapier, J. C. and Hibbs J. B. (1986) Murine cytotoxic activated macrophages inhibit aconitase in tumor cells. Inhibition involves the iron-sulfur prosthetic group and is reversible. $J$. Clin. Invest. 78, 790-797.

Drapier, J. C., Wietzerbin, J. and Hibbs, J. B. (1988) Interferongamma and tumor necrosis factor induce the L-argininedependent cytotoxic effector mechanism in murine macrophages. Eur. J. Immunol. 18, 1587-1592.

Estevez, A. G., Spear, N., Thompson, J. A., Cornwell, T. L., Radi, R., Barbeito, L. and Beckman, J. S. (1998) Nitric oxidedependent production of cGMP supports the survival of rat embryonic motor neurons cultured with brain-derived neurotrophic factor. J. Neurosci. 18, 3708-3714.

Fehsel, K., Kroncke, K. D., Meyer, K. L., Huber, H., Wahn, V. and Kolb-Bachofen, V. (1995) Nitric oxide induces apoptosis in mouse thymocytes. J. Immunol. 155, 2858-2865.

Forrester, K., Ambs, S., Lupold, S. E., Kapust, R. B., Spillare, E. A., Weinberg, W. C., Felley-Bosco, E. Wang, X. W., Geller, D. A., Tzeng, E., Billiar, T. R. and Harris, C. C. (1996) Nitric oxide-induced p53 accumulation and regulation of inducible nitric oxide synthase expression by wild-type p53. Proc. Natl. Acad. Sci. USA 93, 2442-2447.

Genaro, A. M., Hortelano, S., Alvarez, A., Martinez, C. and Bosca, L. (1995) Splenic B lymphocyte programmed cell death is prevented by nitric oxide release through mechanisms involving sustained Bcl-2 levels. J. Clin. Invest. 95, 18841890.

Green, D. R. (2000) Apoptotic pathways: paper wraps stone blunts scissors. Cell 102, 1-4.

Hannun, Y. A. (1994) The sphingomyelin cycle and the second messenger function of ceramide. J. Biol. Chem. 269, 31253128.

Hebestreit, H., Dibbert, B., Balatti, I., Braun, D., Schapowal, A., Blaser, K. and Simon, H. U. (1998) Disruption of fas receptor signaling by nitric oxide in eosinophils. J. Exp. Med. 187, 415425.

Heneka, M. T., Loschmann, P. A., Gleichmann, M., Weller, M., Schulz, J. B., Wullner, U. and Klockgether, T. (1998) Induction of nitric oxide synthase and nitric oxide-mediated apoptosis in neuronal PC12 cells after stimulation with tumor necrosis factor-alpha/lipopolysaccharide. J. Neurochem. 71, 88-94.

Hsu, H., Xiong, J. and Goeddel, D. V. (1995) The TNF receptor 1-associated protein TRADD signals cell death and NF-kappa B activation. Cell 81, 495-504.

Huang, C., Ma, Wy., Ding, M., Bowden, G. T. and Dong, Z. (1997) Direct evidence for an important role of sphingomyelinase in ultraviolet-induced activation of c-Jun Nterminal kinase. J. Biol. Chem. 272, 27753-27757.

Hur, G. H., Kim, Y. B. and Shin, S. H. (1998) 2-chloroethyl Sulfide Induces Apoptosis and Necrosis in Thymocytes. $J$. 
Biochem. Mol. Biol. 31, 183-188.

Huwiler, A., Pfeilschifter, J. and van den Bosch, H. (1999) Nitric oxide donors induce stress signaling via ceramide formation in rat renal mesangial cells. J. Biol. Chem. 274, 7190-7195.

Ignarro, L. J., Buga, G. M., Wood, K. S., Byrns, R. E. and Chaudhuri G. (1987) Endothelium-derived relaxing factor produced and released from artery and vein is nitric oxide. Proc. Natl. Acad. Sci. USA 84, 9265-9269.

Jacotot, E., Costantini, P., Laboureau, E., Zamzami, N., Susin, S. A. and Kroemer, G. (1999) Mitochondrial membrane permeabilization during the apoptotic process. Ann. N. Y. Acad. Sci. 887, 18-30.

Jun, C. D., Oh, C. D., Kwak, H. J., Pae, H. O., Yoo, J. C., Choi, B. M., Chun, J. S., Park, R. K. and Chung H. T. (1999a) Overexpression of protein kinase $\mathrm{C}$ isoforms protects RAW 264.7 macrophages from nitric oxide-induced apoptosis: involvement of c-Jun N-terminal kinase/stress-activated protein kinase, p38 kinase, and CPP-32 protease pathways. J. Immunol. 162, 3395-3401.

Jun, C. D., Pae, H. O., Kwak, H. J., Yoo, J. C., Choi, B. M., Oh, C. D., Chun, J. S., Paik, S. G., Park, Y. H. and Chung, H. T. (1999b) Modulation of nitric oxide-induced apoptotic death of HL-60 cells by protein kinase $\mathrm{C}$ and protein kinase A through mitogen-activated protein kinases and CPP32-like protease pathways. Cell Immunol. 194, 36-46.

Kim, H., Shim, J., Han, P.L. and Choi, E. J. (1997a) Nitric oxide modulates the c-Jun $\mathrm{N}$-terminal kinase/stress-activated protein kinase activity through activating c-Jun $\mathrm{N}$-terminal kinase. Biochemistry 36, 13677-13681.

Kim, H. Y. (1995) Ginsenoside RgI stimulates nitric oxide release in pulmonary artery endothelial cells in culture. J. Biochem. Mol. Biol. 28, 301-305.

Kim, S. S., Kim, Y. S., Jung, Y. W., Choi, H. I., Shim, M. J. and Kim, T. U. (1999a) Taxol-induced apoptosis and nuclear transloation of mitogen-activated protein (MAP) kinase in HeLa Cells. J. Biochem. Mol. Biol. 32, 379-384.

Kim, T. H., Zhao, Y., Barber, M. J., Kuharsky, D. K. and Yin, X. M. (2000a) Bid-induced cytochrome c release is mediated by a pathway independent of mitochondrial permeability transition pore and Bax. J. Biol. Chem. 275, 39474-39481.

Kim, Y. M., Bergonia, H. and Lancaster, J. R. (1995a) Nitrogen oxide-induced autoprotection in isolated rat hepatocytes. FEBS Lett. 374, 228-232.

Kim, Y. M., Bergonia, H. A., Muller, C., Pitt, B. R., Watkins, W. D. and Lancaster, J. R. Jr. (1995) Loss and degradation of enzyme-bound heme induced by cellular nitric oxide synthesis. J. Biol. Chem. 270, 5710-5713.

Kim, Y. M., Chung, H. T., Kim, S. S., Han, J. A., Yoo, Y. M., Kim, K.M., Lee, G. H., Yun, H. Y., Green, A., Li, J., Simmons, R. L. and Billiar, T. R. (1999) Nitric oxide protects PC12 cells from serum deprivation-induced apoptosis by cGMP-dependent inhibition of caspase signaling. J. Neurosci. 19, 6740-6747.

Kim, Y. M., Chung, H. T., Simmons, R. L. and Billiar, T. R. (2000b) Cellular non-heme iron content is a determinant of nitric oxide-mediated apoptosis, necrosis, and caspase inhibition. J. Biol. Chem. 275, 10954-10961.

Kim, Y. M., de Vera, M. E., Watkins, S. C. and Billiar, T. R. (1997b) Nitric oxide protects cultured rat hepatocytes from tumor necrosis factor-alpha-induced apoptosis by inducing heat shock protein 70 expression. J. Biol. Chem. 272, 1402-1411.

Kim, Y. M., Kim, T. H., Chung, H. T., Talanian, R. V., Yin, X. M. and Billiar, T. R. (2000c) Nitric oxide prevents tumor necrosis factor alpha-induced rat hepatocyte apoptosis by the interruption of mitochondrial apoptotic signaling through Snitrosylation of caspase-8. Hepatology 32, 770-778.

Kim, Y. M., Kim, T. H., Seol, D. W., Talanian, R. V. and Billiar, T. R. (1998) Nitric oxide suppression of apoptosis occurs in association with an inhibition of Bcl-2 cleavage and cytochrome c release. J. Biol. Chem. 273, 31437-31441.

Kim, Y. M., Talanian, R. V. and Billiar, T. R. (1997c) Nitric oxide inhibits apoptosis by preventing increases in caspase-3-like activity via two distinct mechanisms. J. Biol. Chem. 272, 3113831148 .

Kolb, J. P. (2000) Mechanisms involved in the pro- and antiapoptotic role of NO in human leukemia. Leukemia 14, 16851694.

Kolesnick, R. and Golde, D. W. (1994) The sphingomyelin pathway in tumor necrosis factor and interleukin-1 signaling. Cell 77, 325-328.

Kroemer, G., Petit, P. X., Zamzami, N., Vayssiere, J. L. and Mignotte, B. (1995) The biochemistry of programmed cell death. FASEB J. 9, 1277-1287.

Kronke, K-D., Fehsel, K and Kolb-Bachofen, V. (1995) Inducible nitric oxide synthase and its product nitric oxide, a small molecule with complex biological activities. Biol. Chem. Hoppe-Seyler 376, 327-343.

Kwon, Y. G., Min, J. K., Kim, K. M., Lee, D. J., Billiar, T. R. and Kim, Y. M. (2001) Sphingosine 1-phosphate protects human umbilical vein endothelial cells from serum-deprived apoptosis by nitric oxide production. J. Biol. Chem. 276, 10627-33.

Lander, H. M., Jacovina, A. T., Davis, R. J. and Tauras, J. M. (1996) Differential activation of mitogen-activated protein kinases by nitric oxide-related species. J. Biol. Chem. 271, 19705-19709.

Li, H., Zhu, H., Xu, C. J. and Yuan, J. (1998) Cleavage of BID by caspase 8 mediates the mitochondrial damage in the Fas pathway of apoptosis. Cell 94, 491-501.

Li, H., Zhu, H., Xu, C. J. and Yuan, J. (1998) Cleavage of BID by caspase 8 mediates the mitochondrial damage in the Fas pathway of apoptosis. Cell 94, 491-501.

Li, J., Billiar, T. R., Talanian, R. V. and Kim, Y. M. (1997b) Nitric oxide reversibly inhibits seven members of the caspase family via S-nitrosylation. Biochem. Biophys. Res. Commun. 240, 419424.

Li, J., Yang, S. and Billiar, T. R. (2000) Cyclic nucleotides suppress tumor necrosis factor alpha-mediated apoptosis by inhibiting caspase activation and cytochrome $c$ release in primary hepatocytes via a mechanism independent of Akt activation. J. Biol. Chem. 275, 13026-13034.

Li, Y., Maher, P. and Schubert, D. (1997a) Requirement for cGMP in nerve cell death caused by glutathione depletion. J. Cell Biol. 139, 1317-1324.

Lin, K. T., Xue, J. Y., Nomen, M., Spur, B. and Wong, P. Y. (1995) Peroxynitrite-induced apoptosis in HL-60 cells. J. Biol. Chem. 270, 16487-16490.

Liu, D., Pavlovic, D., Chen, M. C., Flodstrom, M., Sandler, S. and Eizirik, D. L. (2000) Cytokines induce apoptosis in beta-cells isolated from mice lacking the inducible isoform of nitric oxide 
synthase (iNOS-/-). Diabetes 49, 1116-1122.

Liu, Z. G., Hsu, H., Goeddel, D. V. and Karin, M. (1996) Dissection of TNF receptor 1 effector functions: JNK activation is not linked to apoptosis while NF-kappaB activation prevents cell death. Cell 87, 565-576.

Loweth, A. C., Williams, G. T., Scarpello, J. H. and Morgan, N. G. (1997) Evidence for the involvement of cGMP and protein kinase $\mathrm{G}$ in nitric oxide-induced apoptosis in the pancreatic Bcell line, HIT-T15. FEBS Lett. 400, 285-288.

Lui, X., Kim, C. N., Yang, J., Jemmerson, R. and Wang, X. (1996) Induction of apoptotic program in cell-free extracts: requirement for dATP and cytochrome c. Cell 86, 147-157.

Luo, X., Budihardjo, I., Zou, H., Slaughter, C. and Wang, X. (1998) Bid, a Bcl2 interacting protein, mediates cytochrome c release from mitochondria in response to activation of cell surface death receptors. Cell 94, 481-490.

Madesh, M., Ramachandran, A. and Balasubramanian, K. A. (1999) Nitric oxide prevents anoxia-induced apoptosis in colonic HT29 cells. Arch. Biochem. Biophys. 366, 240-248.

Mannick, J. B., Asano, K., Izumi, K., Kieff, E. and Stamler, J. S. (1994) Nitric oxide produced by human B-lymphocytes inhibits apoptosis and Epstein-Barr virus reactivation. Cell 79, 11371146.

Mathias, S., Pena, L. A. and Kolesnick, R. N. (1998) Signal transduction of stress via ceramide. Biochem. J. 335, 465-480.

McDaniel, M. L., Corbett, J. A., Kwon, G. and Hill, J. R. (1997) A role for nitric oxide and other inflammatory mediators in cytokine-induced pancreatic beta-cell dysfunction and destruction. Adv. Exp. Med. Biol. 426, 313-319.

Messmer, U. K. and Brune, B. (1996) Nitric oxide-induced apoptosis: p53-dependent and p53-independent signaling pathways. Biochem. J. 319, 299-305.

Messmer, U. K., Lapetina, E. G. and Brune B. (1995) Nitric oxide-induced apoptosis in RAW 264.7 macrophages is antagonized by protein kinase $\mathrm{C}$ - and protein kinase Aactivating compounds. Mol. Pharmacol. 47, 757-765.

Messmer, U. K., Reimer, D. M., Reed, J. C. and Brune, B. (1996) Nitric oxide induced poly(ADP-ribose) polymerase cleavage in RAW 264.7 macrophage apoptosis is blocked by Bcl-2. FEBS Lett. 384, 162-166.

Minden, A., Lin, A., Claret, F. X., Abo, A. and Karin, M. (1995) Selective activation of the JNK signaling cascade and c-Jun transcriptional activity by the small GTPases Rac and Cdc42Hs. Cell 81, 1147-1157.

Moncada, S. Palmer, R. M. J. and Higgs, E. A. (1991) Nitric oxide: physiology, pathophysiology, and pharmacology. Pharmacol. Rev. 43, 109-142.

Mortensen, K., Skouv, J., Hougaard, D. M. and Larsson, L. I. (1999) Endogenous endothelial cell nitric-oxide synthase modulates apoptosis in cultured breast cancer cells and is transcriptionally regulated by p53. J. Biol. Chem. 274, 3767937684.

Mosser, D. D., Caron, A. W., Bourget, L., Meriin, A. B., Sherman, M. Y., Morimoto, R. I. and Massie B. (2000) The chaperone function of hsp70 is required for protection against stress-induced apoptosis. Mol. Cell Biol. 20, 7146-7159.

Muzio, M., Chinnaiyan, A. M., Kischkel, F. C., O'Rourke, K., Shevchenko, A., Ni J. Scaffidi, C., Bretz, J. D., Zhang, M., Gentz, R., Mann, M., Krammer P. H., Peter, M. E. and Dixit, V. M. (1996) FLICE, a novel FADD-homologous ICE/CED-3- like protease, is recruited to the CD95 (Fas/APO-1) death-inducing signaling complex. Cell 85, 817-827.

Nathan, C. (1992) Nitric oxide as a secretory product of mammalian cells. FASEB J. 6, 3051-3064.

Noack, E. and Murphy, M. (1991) Oxidative stress; in Oxidants and Antioxidants, Sies, H. (ed.), pp. 445-489, Academic Press, San Diego, California.

Oh-hashi, K., Maruyama, W., Yi, H., Takahashi, T., Naoi, M. and Isobe, K. (1999) Mitogen-activated protein kinase pathway mediates peroxynitrite-induced apoptosis in human dopaminergic neuroblastoma SH-SY5Y cells. Biochem. Biophys. Res. Commun. 263, 504-509.

Ou, J., Carlos, T. M., Watkins, S. C., Saavedra, J. E., Keefer, L. K., Kim, Y. M., Harbrecht, B. G. and Billiar, T. R. (1997) Differential effects of nonselective nitric oxide synthase (NOS) and selective inducible NOS inhibition on hepatic necrosis, apoptosis, ICAM-1 expression, and neutrophil accumulation during endotoxemia. Nitric Oxide 1, 404-416.

Palmer, R. M., Rees, D. D., Ashton, D. S. and Moncada, S. (1988) L-arginine is the physiological precursor for the formation of nitric oxide in endothelium-dependent relaxation. Biochem. Biophys. Res. Commun. 153, 1251-1256.

Pastorino, J. G., Tafani, M., Rothman, R. J., Marcinkeviciute, A., Hoek, J. B., Farber, J. L. and Marcineviciute, A. (1999) Functional consequences of the sustained or transient activation by $\mathrm{Bax}$ of the mitochondrial permeability transition pore. $J$. Biol. Chem. 274, 31734-31739.

Poderoso, J. J., Carreras, M. C., Lisdero, C., Riobo, N., Schopfer, F. and Boveris A. (1996) Nitric oxide inhibits electron transfer and increases superoxide radical production in rat heart mitochondria and submitochondrial particles. Arch. Biochem. Biophys. 328, 85-92.

Rossig, L., Haendeler, J., Hermann, C., Malchow, P., Urbich, C., Zeiher, A. M. and Dimmeler S. (2000) Nitric oxide downregulates MKP-3 mRNA levels: involvement in endothelial cell protection from apoptosis. J. Biol. Chem. 275, 25502-25507.

Saavedra, J. E., Billiar, T. R., Williams, D. L., Kim, Y. M., Watkins, S. C. and Keefer, L. K. (1997) Targeting nitric oxide (NO) delivery in vivo. Design of a liver-selective NO donor prodrug that blocks tumor necrosis factor-alpha-induced apoptosis and toxicity in the liver. J. Med. Chem. 40, 19471954.

Sakahira, H., Enari, M. and Nagata, S. (1998) Cleavage of CAD inhibitor in CAD activation and DNA degradation during apoptosis. Nature 391, 96-99.

Saleh, A., Srinivasula, S. M., Balkir, L., Robbins, P. D. and Alnemri E. S. (2000) Negative regulation of the Apaf-1 apoptosome by Hsp70. Nat. Cell Biol. 2, 476-483.

Salgo, M. G., Squadrito, G. L. and Pryor W. A. (1995) Peroxynitrite causes apoptosis in rat thymocytes .Biochem. Biophys. Res. Commun. 215, 1111-1118.

Sata, M., Kakoki, M., Nagata, D., Nishimatsu, H., Suzuki, E., Aoyagi, T., Sugiura, S., Kojima, H., Nagano, T., Kangawa, K., Matsuo, H., Omata, M., Nagai, R. and Hirata, Y. (2000) Adrenomedullin and nitric oxide inhibit human endothelial cell apoptosis via a cyclic GMP-independent mechanism. Hypertension 36, 83-88.

Sawada, M., Nakashima, S., Banno, Y., Yamakawa, H., Hayashi, K., Takenaka, K., Nishimura, Y., Sakai, N. and Nozawa, Y. (2000) Ordering of ceramide formation, caspase activation, and 
Bax/Bcl-2 expression during etoposide-induced apoptosis in C6 glioma cells. Cell Death Differ. 7, 761-772.

Schmidt, H. H. H. W. (1992) NO, CO and OH: Endogenous soluble guanylyl cyclase-activating factors. FEBS Lett. 307, 102-107.

Schmidt, H. H. H. W., Lohmann, S. M., and Walter, U. (1993) The nitric oxide and cGMP signal transduction system: regulation and mechanism of action. Biochim. Biophys. Acta 1178, $153-175$

Schmidt, H. H. H. W. and Walter U. (1994) NO at work. Cell 78, 919-925.

Schubert, K. M., Scheid, M. P. and Duronio, V. (2000) Ceramide inhibits protein kinase B/Akt by promoting dephosphorylation of serine 473. J. Biol. Chem. 275, 13330-13335.

Shimojo, T., Hiroe, M., Ishiyama, S., Ito, H., Nishikawa, T. and Marumo, F. (1999) Nitric oxide induces apoptotic death of cardiomyocytes via a cyclic-GMP-dependent pathway. Exp. Cell Res. 247, 38-47.

Soh, J. W., Mao, Y., Kim, M. G., Pamukcu, R., Li, H., Piazza, G. A., Thompson, W. J. and Weinstein, I. B. (2000) Cyclic GMP mediates apoptosis induced by sulindac derivatives via activation of c-Jun NH2-terminal kinase 1. Clin. Cancer Res. 6, 4136-4141.

Stamler, J. S. (1994) Redox signaling: nitrosylation and related target interactions of nitric oxide. Cell 78, 931-936.

Strum, J. C., Small, G. W., Pauig, S. B. and Daniel, L. W. (1994) 1-beta-D-Arabinofuranosylcytosine stimulates ceramide and diglyceride formation in HL-60 cells. J. Biol. Chem. 269, 15493-15497.

Susin, S. A., Lorenzo, H. K., Zamzami, N., Goodlett, D. R., Aebersold, R., Siderovski, D. P., Penninger, J. M. and Kroemer, G. (1999) Molecular characterization of mitochondrial apoptosis-inducing factor. Nature 397, 441-446.

Taimor, G., Hofstaetter, B. and Piper, H. M. (2000) Apoptosis induction by nitric oxide in adult cardiomyocytes via cGMPsignaling and its impairment after simulated ischemia. Cardiovasc. Res. 45, 588-594.

Takeda, Y, Tashima, M, Takahashi, A., Uchiyama, T. and Okazaki, T. (1999) Ceramide generation in nitric oxide-induced apoptosis. Activation of magnesium-dependent neutral sphingomyelinase via caspase-3. J. Biol. Chem. 274, 1065410660.

Tamatani, M., Ogawa, S., Niitsu, Y. and Tohyama, M. (1998) Involvement of Bcl-2 family and caspase-3-like protease in NO-mediated neuronal apoptosis. J. Neurochem. 71, 15881596.

Tamir, S., deRojas-Walker, T., Wishnok, J. S. and Tannenbaum, S. R. (1996) DNA damage and genotoxicity by nitric oxide. Methods Enzymol. 269, 230-243.

Tepper, C. G., Jayadev, S., Liu, B., Bielawska, A., Wolff, R., Yonehara, S., Hannun, Y. A. and Seldin, M. F. (1995) Role for ceramide as an endogenous mediator of Fas-induced cytotoxicity. Proc. Natl. Acad. Sci. USA 92, 8443-8447.

Thompson, C. B. (1995) Apoptosis in the pathogenesis and treatment of disease. Science 267, 1456-1462.

Thornberry, N. A. and Lazebnik, Y. (1998) Caspases: enemies within. Science 281, 1312-1316.

Tournier, C., Hess, P., Yang, D. D., Xu, J., Turner, T. K., Nimnual, A., Bar-Sagi, D., Jones, S. N., Flavell, R. A. and Davis, R. J. (2000) Requirement of JNK for stress-induced activation of the cytochrome c-mediated death pathway. Science 288, 870-874.

Tzeng, E., Kim, Y. M., Pitt, B. R., Lizonova, A., Kovesdi, I. And Billiar, T. R. (1997) Adenoviral transfer of the inducible nitric oxide synthase gene blocks endothelial cell apoptosis. Surgery 122, 255-263.

Verheij, M., Bose, R., Lin, X. H., Yao, B., Jarvis, W. D., Grant, S., Birrer, M. J., Szabo, E., Zon, L. I., Kyriakis, J. M., Haimovitz-Friedman, A., Fuks, Z. and Kolesnick, R. N. (1996) Requirement for ceramide-initiated SAPK/JNK signaling in stress-induced apoptosis. Nature 380, 75-79.

Wang, J., Zhen, L., Klug, M. G., Wood, D., Wu, X. and Mizrahi, J. (2000) Involvement of caspase 3- and 8-like proteases in ceramide-induced apoptosis of cardiomyocytes. J. Card. Fail. 6, 243-249.

Wyllie, A. H., Kerr, J. F. R. and Currie, A. R. (1980) Cell death: the significance of apoptosis Int. Rev. Cytol. 68, 251-306.

Yang, J., Liu, X., Bhalla, K., Kim, C. N., Ibrado, A. M., Cai, J., Peng, T. I., Jones, D. P. and Wang X. (1997) Prevention of apoptosis by Bcl-2: release of cytochrome $\mathrm{c}$ from mitochondria blocked. Science 275, 1129-1132. 